\title{
The Study of Male-Female Chamfer Angle Effect on Aluminum 6061 Forging at Rotary Friction Welding Process
}

\author{
Yohanes $^{\text {a }}$, Anugra Fikri Azmi ${ }^{\text {b* }}$ and Ridwan Abdurrahman ${ }^{\mathrm{c}}$ \\ a) Laboratory Technology Production Mechanical Engineering Department, Universitas Riau, Indonesia \\ b) Mechanical Engineering Department, Universitas Riau, Indonesia \\ c) Mechanical Engineering Department, Universitas Muhammadyah Riau, Indonesia
}

*Corresponding author: yohanes@ lecturer.unri.ac.id

\author{
Paper History \\ Received: 30-May-2021 \\ Received in revised form: 30-June-2021 \\ Accepted: 30-July-2021
}

$\begin{array}{ll}\text { TO } & \text { : Material starting temperature }\left({ }^{\circ} \mathrm{C}\right) \\ s & : \text { Volume heat capacity }\left(\mathrm{J} / \mathrm{mm}^{3}{ }^{\circ} \mathrm{C}\right) \\ \alpha & : \text { Thermal diffusion }\left(\mathrm{mm}^{2} / \mathrm{s}\right) \\ q 0 / A & : \text { Heat flux }(\mathrm{W} / \mathrm{mm})\end{array}$

\subsection{INTODUCTION}

Welding is one of the techniques of metal splicing by melting part of the parent metal, which is heated by certain temperature with or without pressure, with or without filler metal [1]. The aluminum has often used in the industry for welding processes. The advantage of aluminum have a relatively light weight with a density of $2.7 \mathrm{~g} / \mathrm{cm}^{3}$ or almost $1 / 3$ of the steel type weight, mechanical strength and physical properties can be improved by adding alloy elements [2]. The type of aluminum that is often used in the industry is aluminum series 6061 . Aluminum 6061 classified as aluminum series 6xxx with magnesium and silicon blending elements. This type of alloy can be used in heat treatment and has the good enough properties of cutting capacity and corrosion resistance [3]. However, the weakness of aluminum and its alloys can be reviewed from the connection process, which is difficult to do with liquid welding due to it have a layer of aluminum oxide on its surface. One solution in solving the problem of metal splicing techniques is to used the friction welding $[4,10]$.

The friction welding technology is one of the methods of solid state welding type, where the heat source produced by two metals that rub against each other. The friction welding is one solution to overcome the difficulty of connecting with fusion welding [9]. Some study about the friction welding was carried out by researches [11-15]. Mehta [11] conducted a review on friction-based joining of dissimilar aluminum-steel joints and revealed friction-based splicing process has the potential to obtain good aluminum-steel joints. More, incorporates thick section aluminum to steel with the intermetallic formation of $\mathrm{FeAl}$ can be suppressed through adjustment of the friction welding process [12]. Whilst, based [13], they carried out simulations and experimental test to identify the interfacial morphology to estimate the post-weld microstructure and joint strength of the friction welding process. More, [14] evaluated the effect of initial contact 
geometry on the mechanical properties of frictional aluminum welded joints on the mechanical properties. Regarding to [15], they developed a rotary friction welding machine and revealed the greater pressure exerted on rotary welding machine may effect to large torque value. Furthermore, it is a challenge to investigate the parameters process of friction welding such as friction time, friction pressure, forging time, forging pressure and rotational speed in optimal manner [16].

Kasijanto and Wahjudi [5] concluded in their study that the male-female chamfer method can increase the friction surface area. Therefore, the welding contact area is also increased. However, in this study the timing of forging load is not determined because varied the length of time on friction. So it can cause a change in length that is greater in specimens. Another result of this study is the influence of long friction time on changes in the length of the specimen. As the result is the longer friction time causes a change in length that is greater. This is due to the longer of the friction time, which can increase the temperature to affect greater friction. Therefore, a study is needed to determine the proper forging load.

The success of friction welding is influenced by material properties and working conditions such as: relative velocity between surfaces, applied pressure, temperature formed on the surface, bulk properties of the material, surface conditions and presence of a thin layer on the surface [16]. The surface conditions of the work-specimens such as giving a chamfer angle with variations in the diameter of the forging and the length of the chamfer angle affect the tensile strength value of mild steel [17]. This can be seen with the same forging diameter (the length of the chamfer angle varies) for all chamfer angles. It is due to the tensile strength value of mild steel increase with the greater given chamfer angle. Also with the same chamfer angle length (varied forging diameter) for all chamfer angles causes the tensile strength value of mild steel to increase with the smaller given chamfer angle [17]. This paper purpose is to investigate male-female chamfer angle effect on forging pressure, specimen length and the maximum tensile strength for splicing 6061 aluminum material, which used the rotary friction welding process.

\subsection{METHODOLOGY}

In this study was used analytical method to determine the timing of forging pressure as an initial reference when conducting experimental testing. The material was used a specimen of Aluminum 6061, which be joined by a rotary friction welding with a length of $90 \mathrm{~mm}$ and the diameter of 10 $\mathrm{mm}$. The specimen surface used male-female chamfer angles with variations ranging from $0^{\circ}, 15^{\circ}, 30^{\circ}, 45^{\circ}$ and $60^{\circ}$.

\subsection{Analytical Method Procedure}

For each thermodynamic cycle, the first law of thermodynamics indicates the cyclic integral of work is the same as the cyclic integral heat. This means the net work transferred from the cycle (marked as positive work) is equal to the total heat given to the cycle (marked as positive heat flow) [6]. From the Figure 1 and 2 can be explained that there is one rotating material and the other material, it given axial press force $(p)$ from the $x$-axis resulting in friction on the surface of both materials. The friction occurs in the onset of heat influenced by several factors, namely: the friction surface area, kinetic coefficient of friction, angular velocity and pressure exerted when both materials rub [9].

$$
\oint \delta W=\oint \delta Q
$$

In general, the distribution of pressure is throughout the interface. If all the sliding forces on the interface are assumed to be converted to frictional heat, then the average heat input per unit area and time becomes in the following equation.

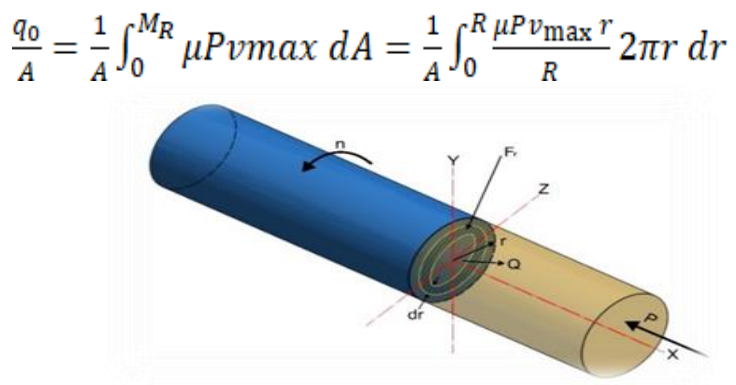

Figure 1: The energy works on welding without using malefemale chamfer angles

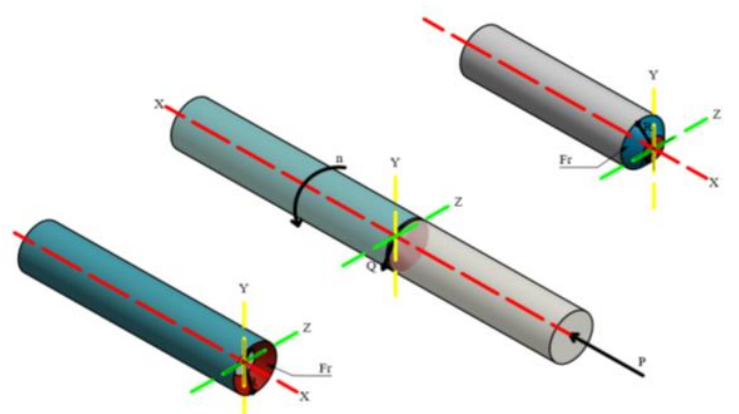

Figure 2: The energy works on welding using male-female chamfer angles

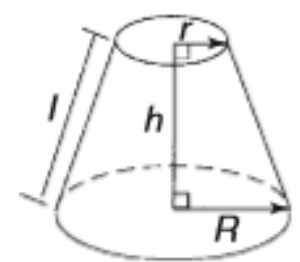

Figure 3: The surface area of cone

$$
=2 / 3 \mu P v_{-} \max
$$

Based on Figure 3 is obtained the Equation 4 to determine the surface area of the friction [7].

$$
\text { Total surface area }=\pi \mathrm{l} \mathrm{R}+\pi \mathrm{l} r+\pi \mathrm{r}^{2}
$$

To obtain a heat flux value that corresponds to the male-female friction surface area model, $\mathrm{r}$ is changed to $\mathrm{R}-\mathrm{x}$, which can be seen in Equation 5.

$\pi l R+\pi l(R-x)+\pi(R-x)^{2}$ 
So, for equations using the male-female chamfer angles is shown in the following equation [8].

$$
\frac{q_{0}}{A}=\frac{1}{A} \int_{0}^{M_{R}} \mu P v d A=\frac{1}{A} \int_{0}^{R} \mu P v_{\max } 2 \pi l+2 \pi R-2 \pi \mathrm{x} d R
$$

$=\frac{2 \pi \mu P v_{-} \max \left(l R+\frac{R^{2}}{2}-x R\right)}{\pi l R+\pi l R-\pi l x+\pi\left(R^{2}+2 R x+x^{2}\right)}$

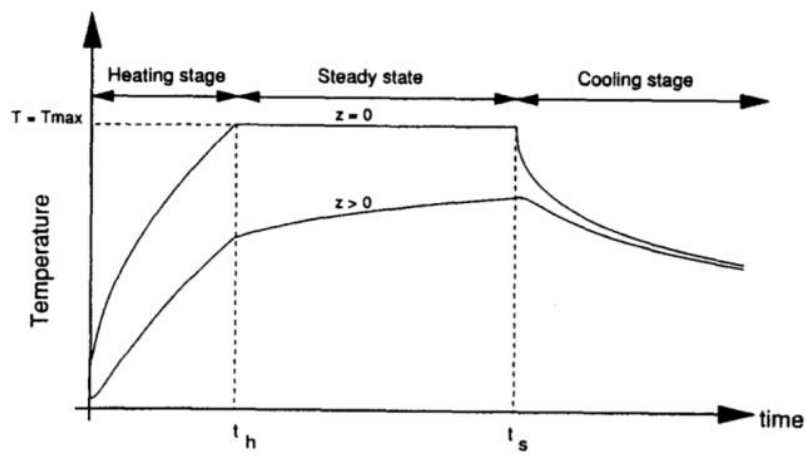

Figure 4: Welding stage [8]

The equations 3 and 7 provide the basis for estimating heat generation on the interface during friction welding. The constant heat generation model was based on the model described by [8]. They states the welding consists of three stages, namely heating, steady state, and cooling, as can be seen in Figure 4.

During the heating stage, the welding interface temperature increases from the ambient temperature to the maximum internal temperature of welding. The time it takes for the welding interface to reach the maximum temperature can be calculated using the following equation:

$t_{h}=\left[\frac{\left(T_{\max }-T_{o}\right) x(s \sqrt{\pi \alpha}}{\left(\frac{q \sigma}{A}\right)}\right]^{2}$

During the steady state, the temperature of the welding interface is assumed to be constant. Therefore, the temperature of the upper work-piece is maintained constantly until the end of welding.

\subsection{Experimental Method Procedure}

In this study was conducted the connection of mild steel material with a length of $90 \mathrm{~mm}$ and diameter of $10 \mathrm{~mm}$. The connection process is done by varying the angle of the chamfer on the frictional surface of the work-piece to be connected. There were 5 variations [17] of chamfer angles that are $0^{\circ}, 15^{\circ}$, $30^{\circ}, 45^{\circ}, 60^{\circ}$ which can be seen in Figures 5-9.

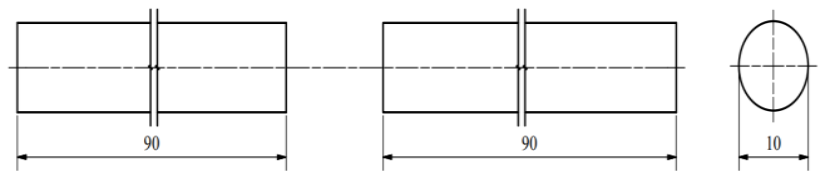

Figure 5: Dimensional male-female chamfer angle of $0^{\circ}$

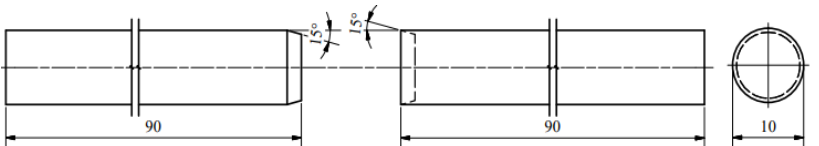

Figure 6: Dimensional male-female chamfer angle of $15^{\circ}$

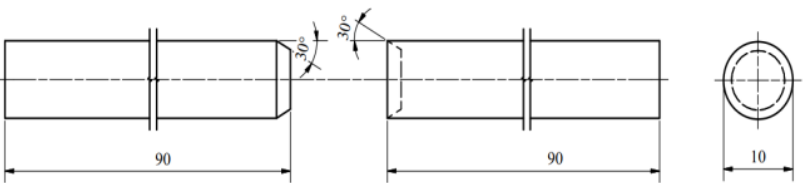

Figure 7: Dimensional male-female chamfer angle of $30^{\circ}$

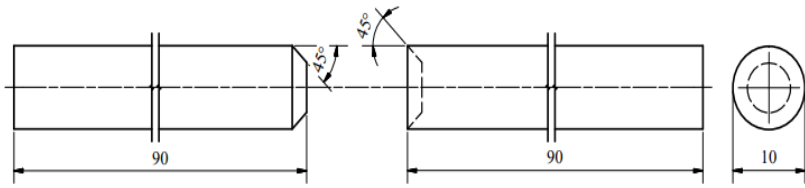

Figure 8: Dimensional male-female chamfer angle of $45^{\circ}$

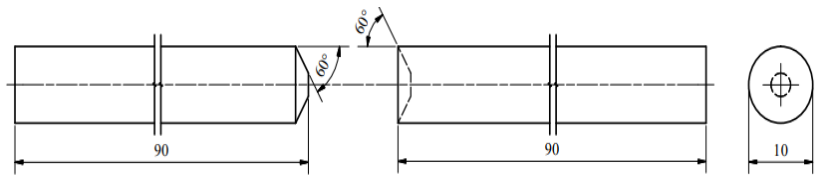

Figure 9: Dimensional male-female chamfer angle of $60^{\circ}$

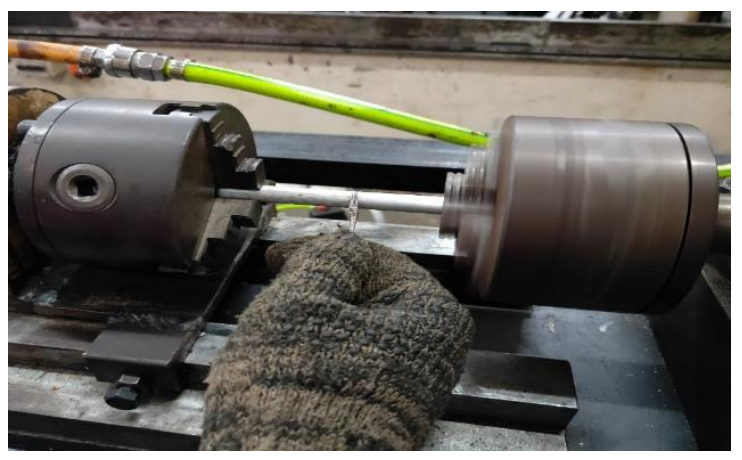

Figure 10: The process of connecting work-pieces with rotary friction welding machine

The connection process was performed using the rotary friction welding, which was given friction load of $0.04 \mathrm{~N} / \mathrm{mm}^{2}$ and the forging load of $0.06 \mathrm{~N} / \mathrm{mm}^{2}$ for 3 seconds. The rotation speed in the connection process was $368 \mathrm{rpm}$. During the connection process of the work-piece with rotary friction welding machine, the temperature on the friction surface was measured using thermocouple. Therefore, the melt point timing can be known well and the timing of forging pressure can be done accurately. In Figure 10 can be seen the process of connecting the work-piece on a rotary friction welding machine.

\subsection{RESULTS AND DISCUSSION}

The result of data was obtained using analytical method and experimental method. 


\subsection{Data Results by Analytical Calculation}

The calculation with analytical method was computed as an initial reference in forging load. The forging pressure value can be calculated using equations 3 and 7, the calculation result can be seen in Figure 11. In Figure 11 is depicted the variation in male-female chamfer angle affects the value of heat flux from the analytical data. The variation in the male-female chamfer angle affects the welding process with the given forging pressure of $0.04 \mathrm{~N} / \mathrm{mm}^{2}$. It was known the larger friction surface area, the greater the heat flux value. The largest heat flux value was found in the male-female chamfer angle of $15^{\circ}$ for heat flux value of $2.89 \mathrm{~W} / \mathrm{mm}^{2}$. The smallest heat flux value was $2.05 \mathrm{~W} / \mathrm{mm}^{2}$, which occurred at the male-female chamfer angle of $0^{\circ}$.

In Figure 12 can be seen the variation in male-female chamfer angle affects the long friction time of the analytical results. The variation in the giving angle of the male-female chamfer causes the friction surface area to be larger, where the greater the value of heat flux, the faster time takes to reach the melting point.

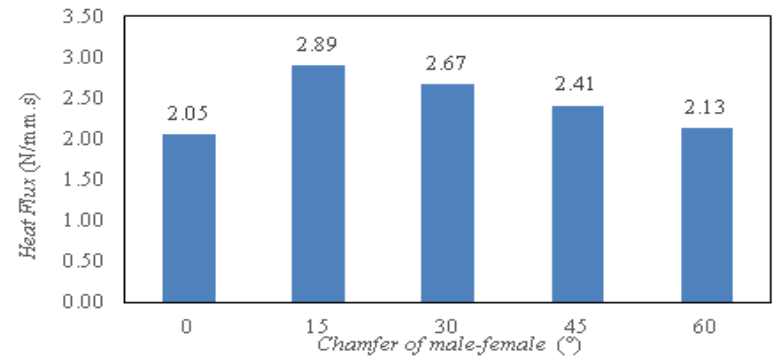

Figure 11: The result of heat flux analytical method

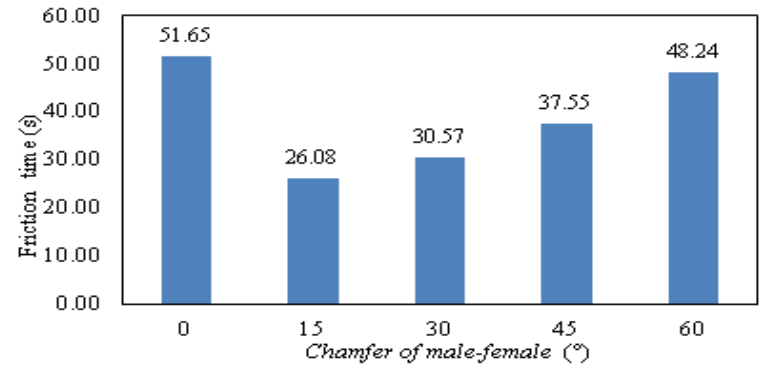

Figure 12: The duration of the swipe of the analytic method

\subsection{Experimental Result}

In experimental tests was obtained the time data of forging pressure. The specimens used cylinders with a length of $90 \mathrm{~mm}$ and a diameter of $10 \mathrm{~mm}$ where the surface of the friction uses male-female chamfer angles with variations ranging from $0^{\circ}$, $15^{\circ}, 30^{\circ}, 45^{\circ}$, and $60^{\circ}$.

In experimental testing, the work-pieces were tested the connection of mild steel material with rotary friction welding machine. The variation of chamfer angles of $0^{\circ}, 15^{\circ}, 30^{\circ}$, $45^{\circ}, 60$. The forging timing of welding process was given for 3 seconds when the work-piece has reached its melting point. The test result can be found in Table 1. In Table 1, it is known that male-female chamfer angle feeding affects the exertion of forging pressure on the connection of aluminum material 6061 on rotary friction welding. The graph of the average forging pressure on male-female chamfer angle can be seen in Figure 18.

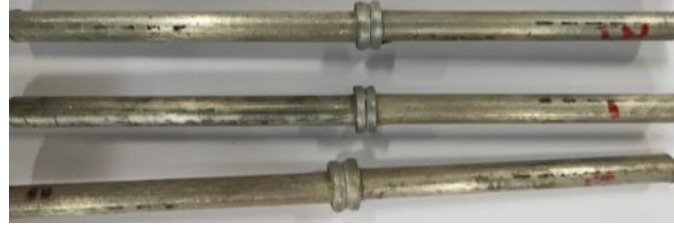

Figure 13: The welding result of male-female chamfer angle of $0^{\circ}$

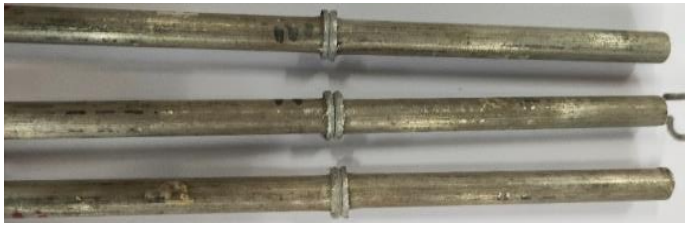

Figure 14: The connection result of male-female chamfer angle of $15^{\circ}$

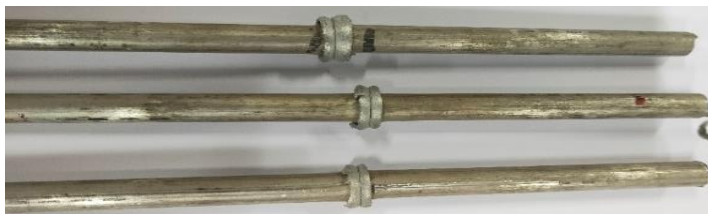

Figure 15: The welding result of male-female chamfer angle of $30^{\circ}$

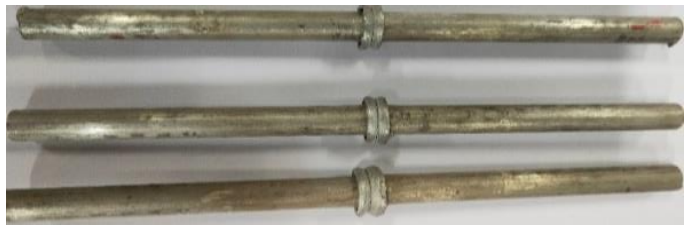

Figure 16: The welding result of male-female chamfer angle of $45^{\circ}$

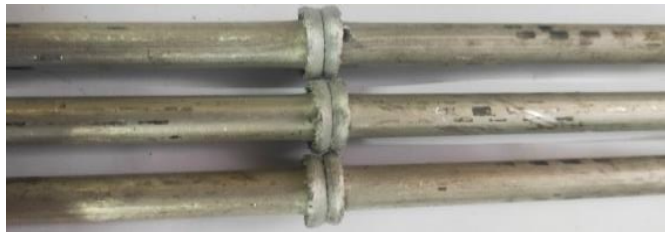

Figure 17: The welding result of male-female chamfer angle of $60^{\circ}$

\subsection{Comparison of pressure forging analytical method versus the experimental method}

In this discussion was conducted to find out whether analytical calculations might be used as an initial reference in the provision of forging pressure in the connection of aluminum material 6061 using rotary friction welding machine.

In Table 2, there is a difference between the timing of forging pressure by analytical method and experimental method. This is due to the thermal properties of different materials, the clarity material used and the limitation of measuring instrument. Therefore, the difference is expressed in the percentage of experimental testing error and calculation with analytical method. The difference is expressed in the percentage of test errors and calculations with analytical method that is depicted in Figure 19. 
Table 1: The result of data experimental test

\begin{tabular}{|c|c|c|c|c|}
\hline \multirow[b]{2}{*}{ eksperiment } & \multirow{2}{*}{$\begin{array}{c}\text { Male } \\
\text { Female } \\
\text { Chamfer } \\
\left.\text { Angle ( }{ }^{\circ}\right)\end{array}$} & \multirow{2}{*}{$\begin{array}{l}\text { Pressure } \\
\text { Friction } \\
\left(\mathrm{N} / \mathrm{mm}^{2}\right)\end{array}$} & \multicolumn{2}{|c|}{ Friction Time (s) } \\
\hline & & & Analytic & Eksperimental \\
\hline 1 & & & & 58 \\
\hline 2 & 0 & 0.04 & 51.65 & 59 \\
\hline 3 & & & & 60 \\
\hline 1 & & & & 30 \\
\hline 2 & 15 & 0.04 & 26.08 & 32 \\
\hline 3 & & & & 29 \\
\hline 1 & & & & 38 \\
\hline 2 & 30 & 0.04 & 30.57 & 35 \\
\hline 3 & & & & 37 \\
\hline 1 & & & & 40 \\
\hline 2 & 45 & 0.04 & 37.55 & 44 \\
\hline 3 & & & & 45 \\
\hline 1 & & & & 55 \\
\hline 2 & 60 & 0.04 & 48.24 & 57 \\
\hline 3 & & & & 53 \\
\hline
\end{tabular}

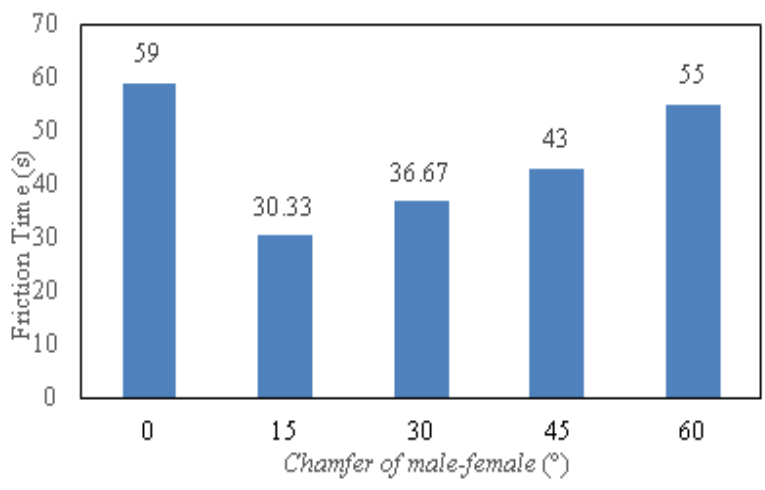

Figure 18: The result of forging pressure duration in experimental method

\subsection{Specimen Length Change Data}

The consequences of to the pressure force and frictional length of the specimens that rubbed against each other, deformation occurred, which resulted in a reduction in length in the specimen. There was a reduction in length that varies with each specimen variation. In Figure 20 can be seen the result between male-female chamfer angle versus the specimen length change.

In Figure 20, it is known that variations in male-female chamfer angles affect length changes in specimens during welding with a given forging pressure of $0.04 \mathrm{~N} / \mathrm{mm}^{2}$. The male-female chamfer angle might cause the friction surface area to be larger. Sequence, the larger the friction surface area, the smaller the length change in the specimen. This is due to the larger the friction surface area, the faster friction time needed to reach the melting point of the specimen. Therefore, the material was slightly wasted during the welding process with the given forging pressure of $0.04 \mathrm{~N} / \mathrm{mm}^{2}$.

\subsection{Result of Tensile Test}

The tensile tests were conducted to determine the maximum tensile strength value of the welding specimens.
Table 2: The comparing data between analytical method and experimental method

\begin{tabular}{|c|c|c|c|c|c|}
\hline \multirow[b]{2}{*}{ eksperiment } & \multirow{2}{*}{$\begin{array}{c}\text { Male } \\
\text { Female } \\
\text { Chamfer } \\
\left.\text { Angle ( }{ }^{\circ}\right)\end{array}$} & \multirow{2}{*}{$\begin{array}{l}\text { Pressure } \\
\text { Friction } \\
\left(\mathrm{N} / \mathrm{mm}^{2}\right)\end{array}$} & \multicolumn{2}{|c|}{ Friction Time (s) } & \multirow[b]{2}{*}{ Error (\%) } \\
\hline & & & Analytic & Eksperimental & \\
\hline 1 & \multirow{3}{*}{0} & \multirow{3}{*}{0.04} & \multirow{3}{*}{51.65} & 58 & \multirow{3}{*}{12.44} \\
\hline 2 & & & & 59 & \\
\hline 3 & & & & 60 & \\
\hline 1 & \multirow{3}{*}{15} & \multirow{3}{*}{0.04} & \multirow{3}{*}{26.08} & 30 & \multirow{3}{*}{13.88} \\
\hline 2 & & & & 32 & \\
\hline 3 & & & & 29 & \\
\hline 1 & \multirow{3}{*}{30} & \multirow{3}{*}{0.04} & \multirow{3}{*}{30.57} & 38 & \multirow{3}{*}{16.53} \\
\hline 2 & & & & 35 & \\
\hline 3 & & & & 37 & \\
\hline 1 & \multirow{3}{*}{45} & \multirow{3}{*}{0.04} & \multirow{3}{*}{37.55} & 40 & \multirow{3}{*}{12.44} \\
\hline 2 & & & & 44 & \\
\hline 3 & & & & 45 & \\
\hline 1 & \multirow{3}{*}{60} & \multirow{3}{*}{0.04} & \multirow{3}{*}{48.24} & 55 & \multirow{3}{*}{12.21} \\
\hline 2 & & & & 57 & \\
\hline 3 & & & & 53 & \\
\hline
\end{tabular}

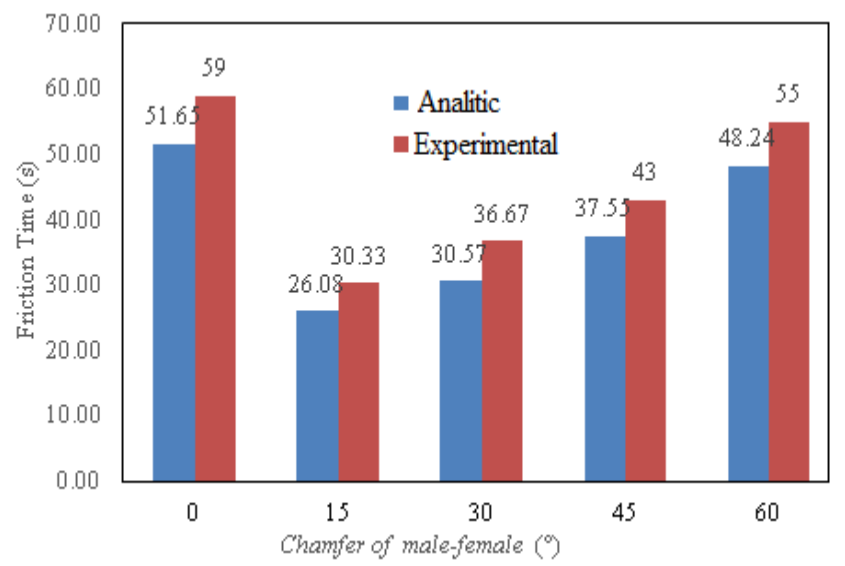

Figure 19: The result of comparing analytic method and experimental method

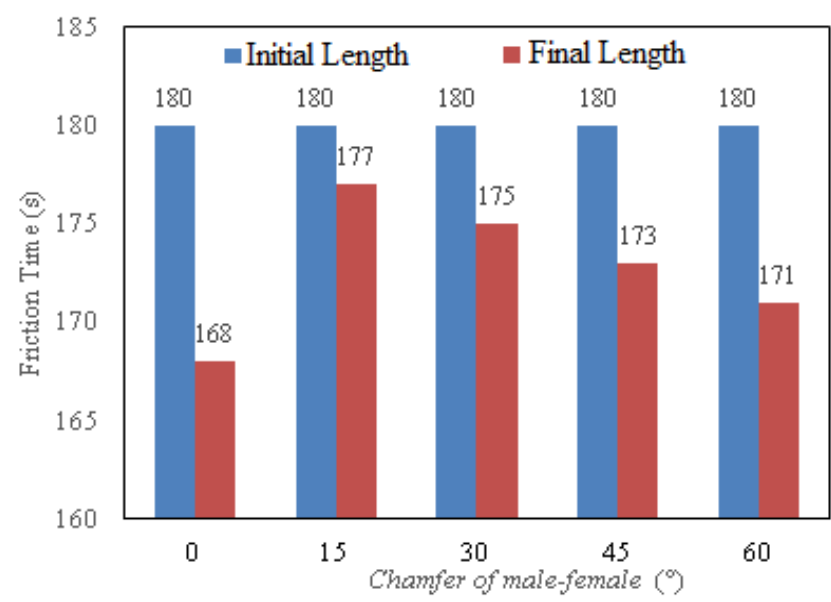

Figure 20: The data result of male-female chamfer angle and specimen length change 


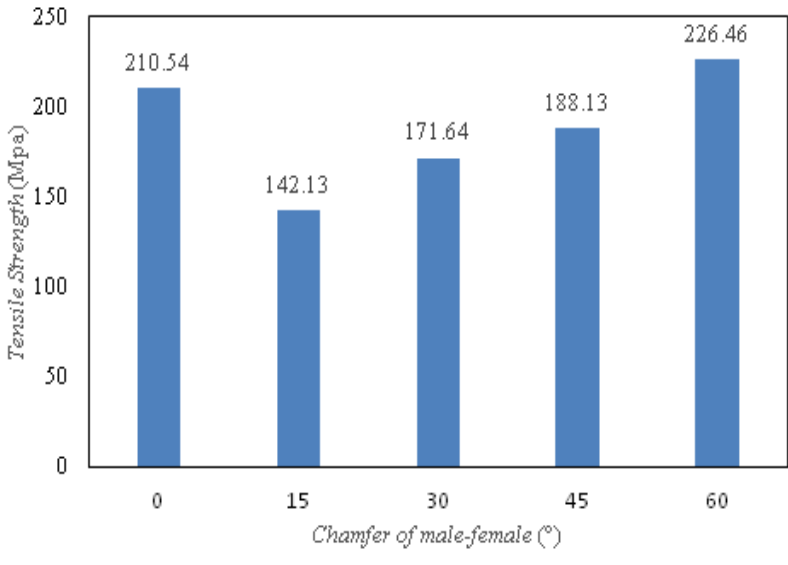

Figure 21: The result of tensile test

In Figure 21, it can be concluded that the highest maximum tensile strength is obtained at a male-female chamfer angle of $60^{\circ}$, which a tensile test value of $226.47 \mathrm{MPa}$. The lowest tensile strength is obtained at male-female chamfer angle of $15^{\circ}$ with a value of tensile test of $142.13 \mathrm{MPa}$. From the data it is known that the variation in male-female chamfer angle affects the maximum tensile strength value of the welding result. This is due to the variation in the giving angle of the male-female chamfer affects the welding process. The angle of the male-female chamfer causes the area of the specimen's friction surface to be larger, then the larger surface area that rubs the higher the temperature.

In addition to the frictional surface area, the long friction time also increases the maximum tensile strength result. This is due to a more evenly distributed temperature. So, it can be analyzed that at the male-female chamfer angle of $60^{\circ}$ is recommended in this research. The male-female chamfer angle of $60^{\circ}$ has the highest tensile strength value compared to other male-female chamfer angles such as at the angle of malefemale chamfer $0^{\circ}, 15^{\circ}, 30^{\circ}$, and $45^{\circ}$. This is in accordance with the research conducted by Kasijanto et al. [5], which states that the male-female chamfer method can increase the surface area of friction, so that the area of contact area of welds also increases. The influence of long-time friction on tensile strength has a linear tendency where the longer the friction time the higher the tensile strength [5]. This is due to the temperature of the friction resulting from more evenly distributed in specimens with a longer friction time.

\subsection{CONCLUSION}

The conclusions obtained from this study are as follows:

1) The timing of forging pressure during the welding process was varies. It is the effect of the giving of male-female chamfer angle variations on the friction surface of the specimen. The longest forging pressure is at the chamfer male-female angle of $0^{\circ}$ and the fastest forging pressure at the male-female chamfer angle of $15^{\circ}$.

2) The changes in specimen length during welding process of each male-female chamfer angle variation is varies due to different of friction length. It is also the longer the friction time, the more material wasted. The largest change in length is at the angle of the male-female chamfer of $0^{\circ}$ and the smallest change in length at the angle of the malefemale chamfer of $15^{\circ}$.

3) Maximum tensile strength against friction welding connection with male-female chamfer angle variations obtains the largest tensile strength result at male-female chamfer angle of $60^{\circ}$ with a value of $226.46 \mathrm{MPa}$. The smallest tensile strength result at a male-female chamfer angle of $15^{\circ}$ with a value of $142.13 \mathrm{MPa}$. Therefore, it can be concluded that at the angle of male-female chamfer of $60^{\circ}$ achieved the optimal result in this research.

\section{REFERENCES}

[1] Rochim, S. dan Hery, S. (2016). Pengantar untuk memahami proses pengelasan logam. Alfabeta. Bandung.

[2] Altenpohl, D. (1982). Aluminum Viewed from Within: An Introduction into the Metallurgy of Aluminum Fabrication. Dusseldorf: Aluminum-Verlag., hal. 3.

[3] ASM International (1998). Properties and Selection: Nonferrous Alloys and Special-Purpose Materials. Metals Handbook. Edisi 2. Materials Park. Ohio.

[4] Uzkut, Mehmet, Ünlu, B.S., Yilmaz, S.S, Akdag, M. (2010). Friction Welding and its Applications in Today's World. Sarajevo. International Symposium on Sustainable Development. Science Book. 710-724.

[5] Kasijanto, W.S. dan Listiono (2018). Pengaruh konfigurasi sudut chamfer male-female dan lama gesek terhadap karakteristik hasil pengelasan dan kekuatan tarik paduan aluminium 6061. Jurnal Energi dan Teknologi Manufaktur (JETM). 1 (2): 01-08.

[6] Bergman, T.L., Incropera, F. P., DeWitt, D.P. \& Lavine, A.S. (2011). Fundamentals of heat and mass transfer. John Wiley \& Sons

[7] Bird, J. (2007). Mathematic Engineering. Edisi 5. Elsevier. Oxford-USA.

[8] Livingston, R.V. (2019). Comparison of heat generation models in finite element analysis of friction welding. Tesis. Brigham Young University.

[9] Yohanes, Y., Siregar, E., Susilawati, A. and Badri, M. (2018). Performance Analysis of Flywheel Addition on Drive System of Rotary Friction Welding Machine. Journal of Ocean, Mechanical And Aerospace -Science and Engineering-, 52(1), 14-19.

[10] Ghias, S.A., Vijaya, R.B, Elanchezhian, C., Siddhartha, D. and Ramanan, N. (2019). Analysis of the friction welding mechanism of low carbon steel-stainless steel and aluminium-copper. Materials Today: Proceedings, 16(2), 766-775, https://doi.org/10.1016/j.matpr.2019.05.157.

[11] Mehta, K.P. (2019). A review on friction-based joining of dissimilar aluminum-steel joints. Journal of Materials Research, 34, 78-96 https://doi.org/10.1557/jmr.2018.332.

[12] Reza-E-Rabby, M., Ross, K., Overman, N.R., Olszta, M.J., McDonnell, M. and Whalen, S.A. (2018). Joining thick section aluminum to steel with suppressed FeAl intermetallic formation via friction stir dovetailing. Scr. Material, 148, 63.

[13] Gupta, V., Upadhyay, P., Fifield, L.S., et al. (2018). Linking process and structure in the friction stir scribe joining of dissimilar materials: A computational approach with experimental support. Journal Manufacturing Process, 32, 615. 
[14] Marlon, A., Pinheiro, Alexandre, Q. Bracarense (2019). Influence of initial contact geometry on mechanical properties in friction welding of dissimilar materials aluminum 6351 T6 and SAE 1020 Steel. Advances in Materials Science and Engineering, https://doi.org/10.1155/2019/1759484.

[15] Yohanes, Y., \& Andri, N. (2020). Performance of dynamometer with sensor type single bar for measuring drive power of rotary friction welding machine. Journal of Ocean, Mechanical and Aerospace -Science and Engineering-, 64(3), 73-80. doi:10.36842/jomase.v64i3.146.
[16] Yohanes, Efriyansyah, M. (2018). Influence of flywheel for drive system of rotary friction welding and chamfer angle variations forging to welding strength. Proceeding of ocean, mechanical and aerospace-science and engineering- 5(1), 33-40.

[17] Yohanes, Partomuan, P. and Sunaryo. (2016). Pengaruh bentuk permukaan forging sambungan las gesek rotary terhadap kekuatan tarik baja mild steel. Jurnal Simposium Nasional Teknologi Terapan, 4, 509-517. 